\title{
A Framework of Web Mining Algorithm-Based Hidden Pattern in India E-Government Application Using Blockchain Technology
}

\author{
Rajeev Kumar \\ Post Doc Researcher, College of Engineering \& Technology, \\ Srinivas University, Mangalore (Karnataka), India \\ OrcidID: 0000-0002-4141-1282, Email: rajeev2009mca@ gmail.com
}

Subject Area: Information Technology.

Type of the Paper: Conceptual Research Review.

Type of Review: Peer Reviewed as per $|\mathrm{C}| \mathrm{O}|\mathrm{P}| \mathrm{E} \mid$ guidance.

Indexed In: OpenAIRE.

DOI: http://doi.org/10.5281/zenodo.4940047

Google Scholar Citation: IJAEML

\section{How to Cite this Paper:}

Rajeev Kumar (2021). A Framework of Web Mining Algorithm-Based Hidden Pattern in India E-Government Application Using Blockchain Technology. International Journal of Applied Engineering and Management Letters (IJAEML), 5(1), 106-114. DOI: http://doi.org/10.5281/zenodo.4940047.

International Journal of Applied Engineering and Management Letters (IJAEML) A Refereed International Journal of Srinivas University, India.

Crossref DOI : https://doi.org/10.47992/IJAEML.2581.7000.0096

(C) With Authors.

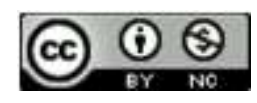

This work is licensed under a Creative Commons Attribution-Non-Commercial 4.0 International License subject to proper citation to the publication source of the work.

Disclaimer: The scholarly papers as reviewed and published by the Srinivas Publications (S.P.), India are the views and opinions of their respective authors and are not the views or opinions of the S.P. The S.P. disclaims of any harm or loss caused due to the published content to any party. 


\title{
A Framework of Web Mining Algorithm-Based Hidden Pattern in India E-Government Application Using Blockchain Technology
}

\author{
Rajeev Kumar \\ Post Doc Researcher, College of Engineering \& Technology, \\ Srinivas University, Mangalore (Karnataka), India \\ OrcidID: 0000-0002-4141-1282, Email: rajeev2009mca@ gmail.com
}

\begin{abstract}
Purpose: The Indian Government should be analyzing these problems and organized a special team who has responsibility for all inquiry and reduced these types of problem and India's Government should be informed about new health projects to people by public relations or advertising. Now, with the advent of data analysis techniques and tools, this process of finding patterns in the behavior of applications can be taken to a next higher level. The methods and algorithms used exclusively in data mining for medical purposes are known as Medical Data Mining. Many studies in the fields of e-government implementation in developed countries are available, but there are not many studies available in India. There is no underlying explanation why considerations apply to the electronic government's introduction, which contributes to a hole in the written audit. The knowledge is hidden among government data set and it is extractable through data mining techniques. The relevant and unchanging design of blockchain technologies could be used to accelerate constant progress to open and distributed energy frameworks and to tackle some problems facing the company.
\end{abstract}

Design/Methodology/Approach: Design \& Implementing the theoretical concept of blockchain is an increasing technology which is seen by many inhabitants as a fundamental weakness because of the general obscurity of the complexities and chances of its execution.

Findings/Result: Although the study being conducted on the thorough analysis of $e$ government results, various questions relating to data collection and methodologies for analyzing these data are yet to be addressed by the potential researchers.

Originality/Value: Huge data analysis will open up options for developing market intelligence to increase the usage and personalization of e-governments.

Paper Type: Conceptual Research Review.

Keywords: e-Governance, Blockchain Technology, Data Mining, Web Mining, Pattern Analysis, Machine learning

\section{INTRODUCTION :}

Online mining is an extended version of data mining. Data mining operates offline, while web mining operates online. Data stored in the (database) data warehouse for data mining and data stored in the server database and weblog for web mining. To locate the shrouded data on the site, a few data mining techniques are used. Internet mining, however, does not necessarily mean applying data mining techniques to the data placed on the Internet. The formulas must be altered with the aim of better satisfying the Web's demands [1]. New methodologies that better suit the properties of Web data should be used. Additionally, data mining algorithms can be used effectively, in addition to constructed knowledge, information retrieval, and natural language processing techniques. Web mining has therefore been developed into a region of self-governing review [2].

\subsubsection{E-Governance}

E-government can be characterized as a component of four factors: administration $(\mathrm{G})$, information and communication innovation (ICT), business process re-building (BPR) and e-resident (EC). It likewise alludes to the delivery of national and state government information and administrations through the 
advanced media to citizens or business or other governmental organizations [3]. According to UNESCO definition (www.unesco.org) "E-administration is the open area's usage of ICT with the point of improving information and administration delivery, encouraging resident participation in the dynamic process... E-administration, which means "electronic governance is the usage of ICT at different degrees of administration, semi government, and open division, to improve the administration and usage of the web to execute their functions of administering, arranging, sorting out, planning, and staffing viably.

\subsubsection{Web-Mining and E-governance}

Big data suggest enormous sizes and diverse data collections. Regular data processing devices and developments on these data sets cannot be of significance [2]. Because data are created at an accelerated pace quickly, it is crucial for developing covered examples and data mining strategies as large data analysis is available [4]. The e-taal are the online entrance for the organization, which provides an overview into the commerce made electronically by residents of different e-governance registration systems [5]. The e-taal provides the data that can be measured by live. It reveals that more than two billion e-exchanges have been performed by Indians over the last one year [6].

The data mining ideas are effectively actualized in a few regions like "Banking," "Visa Business," "Protection," "Client Relationship Management," "Super Store Sales data investigation," "Securities exchange," "Gaming," "System and Security," "Money related Market," "Telecommunication," "Oil and Gas investigation," "Climate Forecasting," "Water Resource," "Horticulture," Healthcare, and so on... In the ongoing past, the administration associations have additionally realized the expected usage of Data Mining on e-administration data [16].

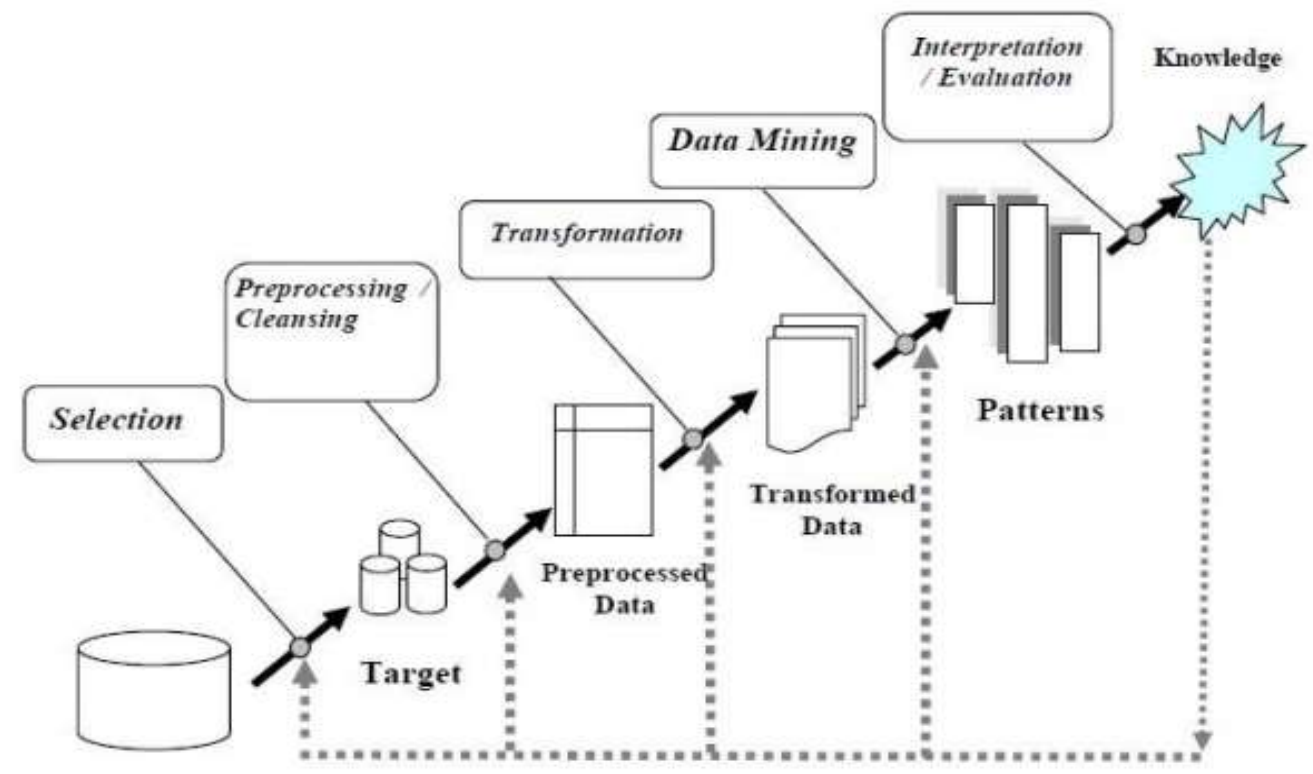

Fig. 1: Data Mining Technique and its implementation in E-Governance [6]

\subsubsection{Blockchain}

Blockchain technology is at present the most critical theme in the IT business. Over the most recent few years, the block chain has stood out as truly newsworthy in business and technology news, as business pioneers keep on appreciating the examples of overcoming adversity of digital currency and brilliant agreements [7][9]. Various significant organizations around the globe have made huge walks in receiving Block chain technology [28-32]. FedEx additionally reported testing of its new Block chain framework for business gracefully chain use with basic payload shipments. Low energy, an energy provider situated in Brooklyn, New York, executed a Block chain framework to improve the following of clean energy [10] [12]. Block chain technology is a rising and disturbing technology, which can change the Information Communication Technology (ICT) administrations at the next level. In this technology, transactions are affirmed and approved with the agreement of majority [8]. No outsider is required for approving the transactions. With the agreement of friend individuals, a block is included 
the Block chain. Each block of block chain contains the exchange details alongside the hash of past block. Thusly, the proprietorship and data respectability are kept up in type of block.

\subsubsection{Surfacing of Blockchain-Based Governance}

The block chain technology potentially permits people and networks to upgrade their co-operations in legislative issues, business and society everywhere, with a remarkable process of disintermediation for huge scope, considering computerized and trustless transactions [11]. This process quickly even changes the principles that support existing political frameworks and governance models, raising doubt about the conventional job of State and centralized establishments. Undoubtedly, many block chain advocates guarantees that the common society compose itself and secure its own advantages all the more viably, by supplanting the customary functions of State with block chain-based administrations and decentralized, open-source stages. Techno-libertarians and crypto-agitators rather hold an increasingly radical position [13][18]. They are commonly disposed to think about the state as an illconceived, superfluous, and irremediably old safe of intensity, and they transparently encourage the usage of the block chain as a freeing power against the very idea of power [14].

\subsection{Background}

A developing measure of informative book with respect to government choices, mandates, rules and regulations is presently conveyed on the web using an assortment of entrances, so residents can peruse and scrutinize them. These accepts, nonetheless, that the information searchers are fit for entrapping the huge volume and multifaceted nature of the legally worded records [17]. Adaptability steps provide a combination of elegant acting, demand response and vitality management [20]. In addition to the revolutionary transition brought about by sufficient vitality capital (DER), and inexhaustible mechanisms of vitality, the gigantic structure of the genius meters in different countries are close to the delicate point of entry to the advanced stage [25]. In the United Kingdom alone, 53 million electricity and gas shrewd meters will be introduced in 2020 [15].

\subsection{Problem}

Block chain technology is a rising and upsetting technology that can change the Information Communication Technology (ICT) organizations at the next level. In this technology, exchanges are asserted and endorsed with the arrangement of greater part. No pariah is required for favoring the exchanges. Thusly, it absolutely discards the activity of pariah. Exchanges are saved in blocks and these blocks are obliged in a consistent movement in the interface list [19]. The first time in year 2009, Satoshi Nakamoto proposed computerized cash called Bit coin. In proposed technology, peer people can support the ownership and usage of the Bit coin-computerized cash and underwriting of controlling position is not needed to favor Block chain exchanges [21]. With understanding of companion people, a block is incorporated into the Block chain [22]. Each block of Block chain contains the trade subtleties close by hash of past block. Accordingly, the ownership and data decency are kept up in a sort of block.

\subsection{Contribution}

The various cutting-edge areas such as hospital management, patient diagnosis, higher medical system, information technology and computing, business management, operations research and optimization, applied mathematics and statistics, simulation techniques, data ware house and data mining the Integration of these disciplines is a prerequisite for effective sharing and usage of information between different government data with prediction in government system. Data mining techniques are used to improve the quality of government scheme and investigations and the usage of the prospective outcome to develop recommendations for a person.

\section{RELATED WORK :}

\subsection{Existing research}

A customary arrangement is to use a main issue of authority, for example, a national bank, who goes about as they believed delegate between executing parties and whose activity is to store, protect the substantial condition of the record and stay up with the latest. If different gatherings should write in the record simultaneously, a focal authority additionally actualized simultaneity control and merges changes in the record [25][29]. In a few events, focal management may not be practical or alluring, as 
it presents middle person costs and requires network clients to confide in an outsider to work the framework. Unified frameworks likewise have noteworthy burdens because of a solitary purpose of disappointment, which renders them more defenseless against both technical disappointment and malevolent assaults.

\subsection{Preliminaries}

The capability takes material, which in general constitutes any arrangement of pieces in the image "0s" and "1s" (which may be a video, an image, or several gigabytes of exchange) and returns a string worth a fixed size as a yield. By structure, a cryptographic hash is a one-way project. This savage-compelling system requires computational exertion that increments exponentially with the quantity of the following zeros [23].

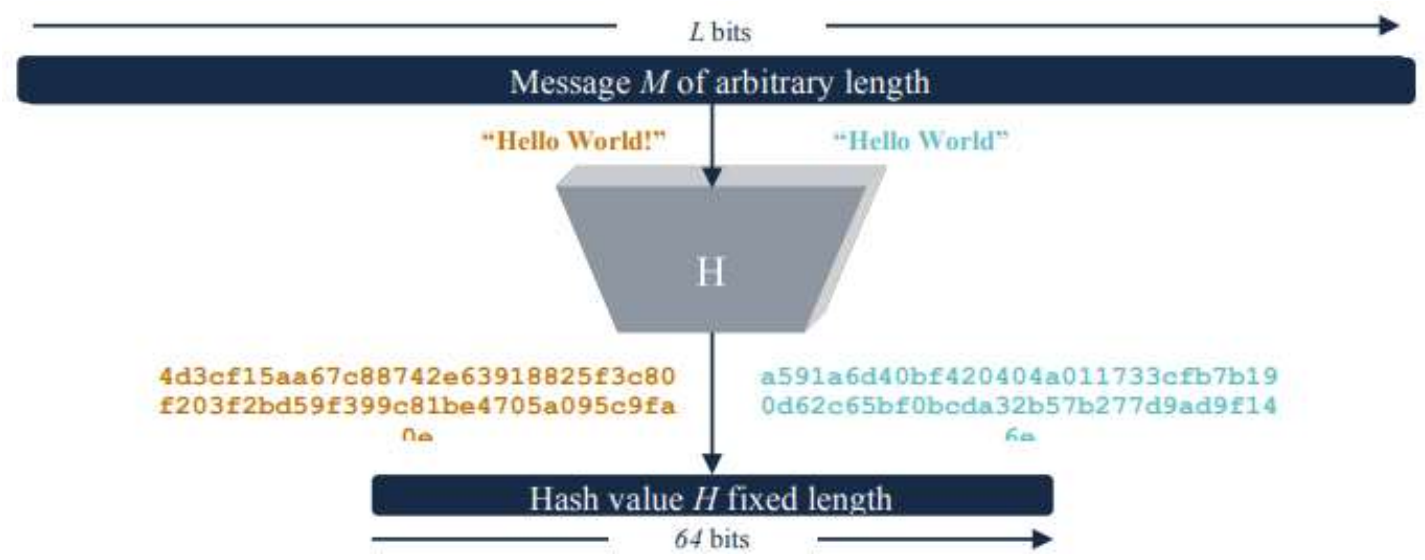

Fig. 2: Perception of how a cryptographic hash work maps data from an area of subjective length to a piece line of a fixed length [11]

\section{OBJECTIVES :}

The objective of this umbrella mission was to create circulated records for the Block chain and their equipment for the exchange of businesses, e-Governance, gracefully chain services, etc. The main objective of the project is to strengthen the relevant record for manufacturing competitiveness, unbroken efficiency, and confidence and so on, through industries in various fields, such as the health-care system, e-Governance models and so on.

Hyper Fabric record: The Blockchain Authorization Infrastructure IBM and Digital Asset designed as Fabric hyper-record. Hyper record engineering promotes chain-code implementation (called Ethereum Smart Agreements), configurable engagement services, and individual functions work, access to data records and configurable agreements, and so on.

\section{METHODOLOGY :}

Exploratory examinations must be adaptable as the course of the investigation would change given the revelation of new experiences or data. Given this, the investigation will be planned with an expansive starting center that at that point limits and gets progressively explicit as the exploration advances. The usage of block chain technology inside the energy segment is another idea and past exploration is viewed as scant. Likewise, the exploration setting is youthful. It therefore gets positive to adjust an exploratory methodology as the reason for the examination, just as the exploration questions, can be reworded as extra discoveries are made. An exploratory methodology is moreover suitable when the information needs are obscure, and there is a need at a beginning phase to examine which further sorts of examination merit seeking after. Along these lines, the consequence of an exploratory examination is frequently a scope of causes or numerous elective alternatives for an answer to a particular issue.

\section{PROPOSED FRAMEWORK :}

\section{BLOCK CHAIN TECHNOLOGY AND ITS APPLICATIONS IN E-GOVERNANCE SERVICES :}

\subsection{Architecture}

Various fans simply advance the block chain as a logically proficient, decentralized and arrangement 
driven open vault, which can have different applications to make residents less subject to governments, yet inside an overall population that is finally established upon the State authority. Techno-libertarians and crypto-instigators rather hold an undeniably extreme position [24]. They are arranged to consider the State a strange, pointless and irremediably old safe of force, and they straightforwardly support the usage of the block chain as a liberating power against the general concept of intensity. As demonstrated by this view, we are at a stage in history when individuals can ceaselessly crush any brought together political establishment through estimation based appropriated understanding and make the conditions for a hopeful culture of reciprocals, depicted by level, rather than dynamic, and structures.

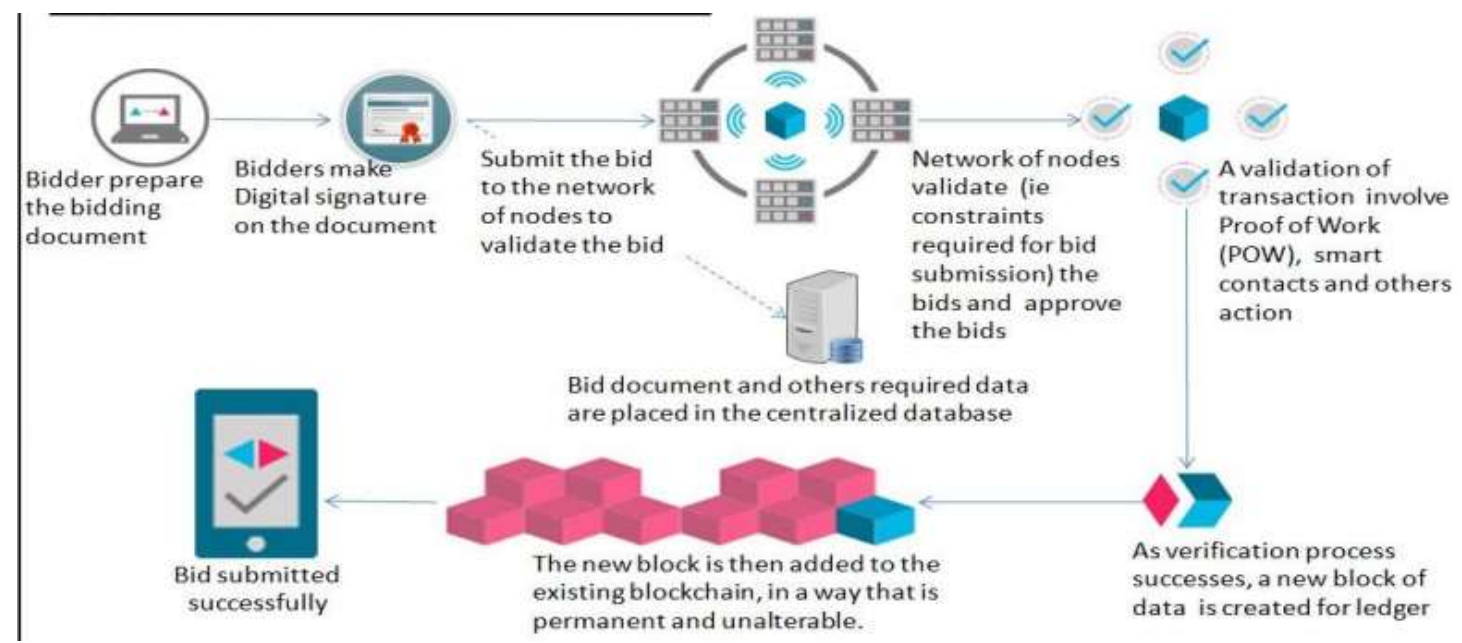

Fig. 3: Block chain Technology and its Applications in E-Governance Services [18]

\subsection{How will mitigate the considerations with framework}

A multi-strategy qualitative methodology will be use, depending on both primary and optional data. The secondary data will report data of both content and non-text character. For instance, recorded introductions, webinars, and sites will be used by and large to increase a more profound comprehension of the examined subject [26]. For the primary data collection both exploratory conversations, semiorganized meetings just as gathering conversations have been investigated. Given the high complexity and oddity of the subject, meetings and conversations will be viewed as the best strategy for data collection as it gives top notch data and contains a larger number of clarifications than, studies [27].

\section{BLOCK CHAIN POTENTIAL EFFECT ON VITALITY ORGANIZATION TASKS :}

Block chain technologies could be applied to an assortment of usage cases identified with the tasks and business cycles of vitality organizations [28].

\subsection{Quantitative Analysis of Proposed framework}

Due to a relatively large data file, there is an outlier for each box in the map. The initial C4.5 has the highest value $(1.27 \mathrm{sec})$ relative to other $\mathrm{C} 4.5$ algorithms enhanced. High performance machines, super machines, etc., are open to users nowadays, however.

\subsection{Clear findings with graph of time relation}

The improved Apriori decreases time consumption by $61.88 \%$ relative to the original Apriori in the first T1 category of transactions, and by $77.80 \%$ in T5. The rate is also increasing as the number of transactions increases. The average time rate reduction in the enhanced Apriori is 67.38 percent. 


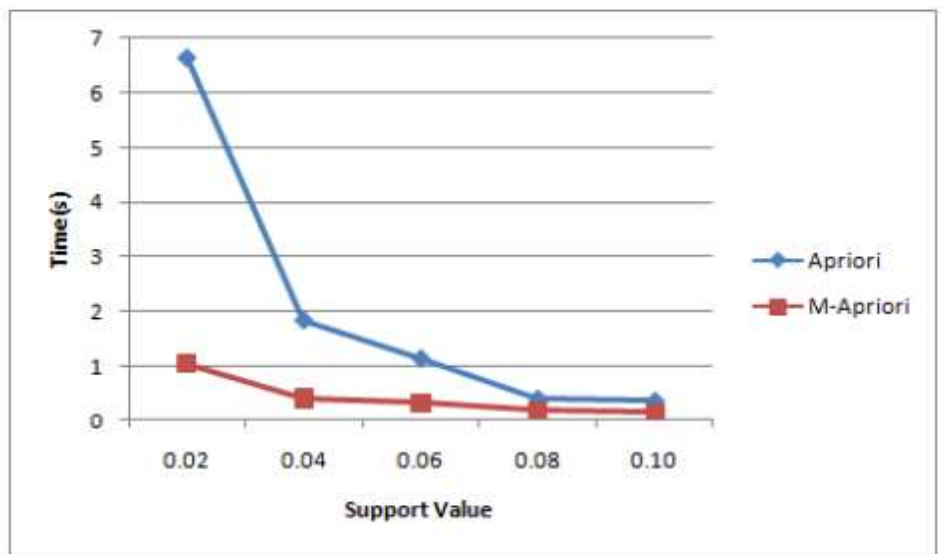

Fig. 4: Time consuming comparison for different values of minimum support

\subsection{Future Scope}

There are henceforth motivations to scrutinize the job of the block chain-based governance as an extraordinary facilitator of individual force, in a flat-out sense. On one hand, the guarantee of enabling people is probably going to stay unfulfilled, due to the prevailing job of business sectors and the theoretical confirmation frameworks of completely circulated block chains. Then again, the process of making light of open foundations, the supremacy of financial matters over governmental issues, and the change of citizens into costumers with the guarantee of more opportunity, efficiency, and equality may cover one more deceptive process of corporatization of legislative issues, which perpetually engages markets in the disservice of citizens. A long way from being new, such a move of intensity from open to private division has been continuous in different structures for a considerable length of time, with huge social and monetary costs.

\section{SUGGESTIONS :}

- The examination ought to be improved since the unbiased conclusions are essentially high.

- Random Forest functions admirably in high-dimensional data, some dimensionality decrease strategy required altogether for the Big data.

- A score of zero shows a nonpartisan supposition. The more sure the score, the more certain the notions of the individual tweezing and the other way around.

- Our examination additionally recommends how assumption investigation results can be used to distinguish the patterns and examples of residents' suppositions driven by functions.

\section{CONCLUSIONS :}

Ethereal is an open-source, public, block chain-based conveyed figuring stage for creating block chainbased applications, additionally called D Apps (Decentralized Applications). It tends to be contemplated that it's the database properties which can settle about the mining procedure to be used for web data. Various leveled grouping bunch the meeting vectors, yet its complexity increments when it's iterated exceeding multiple times. Improved FCM comes out to be the best calculation for use logs as it can deal with unpredictable just as questionable data and a halting rule is used for no. Of cycles. So also, Antbased calculation and its variations can be used for enhancement of the clusters shaped or the usage data. This will aid robotized client personalization of the websites. All newer boundaries and subterranean insect's highlights can be used to build the efficiency of insect calculation.

\section{REFERENCES}

[1] Atzori, M. (2017). Blockchain Technology and Decentralized Governance: is the State Still Necessary? Journal of Governance and Regulation, 6(1), 45-62.

[2] Namasudra, S., Deka, G.C., Johri, P. et al (2020). The Revolution of Blockchain: State-of-the-Art and Research Challenges. Arch Computat Methods Eng, 8(2), 5-8.

[3] Om Pal (2019). Blockchain Technology and its Applications in E-Governance Services, International Journal of Recent Technology and Engineering (IJRTE), 8(4), 76-80. 
[4] Vineet saxena, Deependra Rastogi, Rajeev Kumar (2017). Challenge in route discovery process of dynamically arranged multitier Protocol in wireless network. IEEE Xplore, 182 - 185.

[5] Pradeep Kumar Shah, Rajendra Prasad Pandey, Rajeev Kumar (2017). Vector Quantization with codebook and index compression. IEEE Xplore, 49 - 52.

[6] Gudavalli, M., Kumar, D. S. and Raju, S. V. (2014). Securing E-Governance Services through Biometrics. International Journal of Security and Its Applications, 8(1), 103-112.

[7] Paolo Tasca (2019). A Taxonomy of Blockchain Technologies: Principles of Identification and Classification. Journal LEDGER, 4(1), 1-39.

[8] Sangeetha G. (2015). Efficient Framework of e-Government for Mining Knowledge from Massive Grievance Redressal Data, International Journal of Advanced Research in Computer and Communication Engineering, 4(5), 10-14.

[9] Krishna Kumar Verma (2015). Exploring Role and Associated Challenges of Data Mining Technique and it's Implementation in E-Governance, International Journal of Advanced Research in Computer Engineering \& Technology (IJARCET), 4(8), 62-67.

[10] Singh, S. K., Rathore, S., \& Park, J. H. (2019). Block IoT Intelligence: A blockchain-enabled intelligent IoT architecture with artificial intelligence. Future Generation Computer Systems, 110(1), 721-743.

[11] Singh, S. K., Salim, M. M., Cho, M., Cha, J., Pan, Y., \& Park, J. H. (2019). Smart contract-based pool hopping attack prevention for blockchain networks. Symmetry, 11(7), 941-943.

[12] Gupta, A., Kumar, R. and Tiwari, M. K. (2020). Taxonomy of Link Based web Spammers using Mining Optimized PageRank Algorithm for e-Governance. International Conference on Intelligent Engineering and Management (ICIEM), London, United Kingdom, 155-159.

[13] Junaid, M. J. A. and Kumar, R. (2020). Data Science and Its Application in Heart Disease Prediction," International Conference on Intelligent Engineering and Management (ICIEM), London, United Kingdom, 396-400.

[14] Smart Contracts. Available online: https://blockchainhub.net/smart-contracts/ (accessed on 12 March 2019).

[15] Amit Kumar, Naveen Kumar Tiwari, Rajeev Kumar (2018). A Comprehensive Study of Lip Controlled Human Computer Interface using Machine Learning. International Journal of Engineering Research and Applications (IJERA), 08(01), 69-72.

[16] Desai, P. (2014). Data Mining Prediction Using Data Mining Extensions (DMX): A Case Study on E-Governance Birth Registration Data Mining Model. International Journal of Advanced Research in Engineering and Technology (IJARET), 5(6), 23-26.

[17] Yaeger, K., Martini, M., Rasouli, J. Costa, A. (2019). Emerging Blockchain Technology Solutions for Modern Healthcare Infrastructure. J. Sci. Innov. Med., 2(1), 10-13.

[18] Gaggioli (2018). A. Blockchain Technology: Living in a Decentralized Everything. Cyberpsychol. Behav. Soc. Netw., 21(1), 65-66.

[19] Arvind Jaiswal, Rajeev Kumar (2020). Review on Machine Learning algorithm in Cancer prognosis and prediction. International Journal of All research Education \& Scientific Methods, 8(06), 23-26.

[20] Macrinici, D., Cartofeanu, C., Gao, S. (2018). Smart contract applications within blockchain technology: A systematic mapping study. Telemat. Inform. 35(1), 2337-2354.

[21] Andoni, M.; Robu, V.; Flynn, D.; Abram, S.; Geach, D.; Jenkins, D.; McCallum, P.; Peacock, A. (2019). Blockchain technology in the energy sector: A systematic review of challenges and opportunities. Renew. Sustain. Energy Rev., 100(1), 143-174. 
[22] Meenu, Sandeep Kumar, V. K. Panchal and Rajeev Kumar (2019). Evolution of New Integrated Haze Removal Algorithm Based on Haze Line. International Journal of Engineering and Advanced Technology (IJEAT), 8(06), 184-189.

[23] Ana Ribeiro, Filipe Portela, Manuel Santos, António Abelha, José Machado and Fernando Rua (2017). Patients' Admissions in Intensive Care Units: A Clustering Overview. Information science, $8(1), 23-24$.

[24] Zhengxing Huang, Jose M. Juarez, and Xiang Li (2017). Data Mining for Biomedicine and Healthcare, Hindawi Journal of Healthcare Engineering, 17(1), 19-23.

[25] Singh, S. K., Jeong, Y. S., \& Park, J. H. (2020). A deep learning-based IoT-oriented infrastructure for secure smart City. Sustainable Cities and Society, 60(1), 102-104

[26] Singh, S. K., Salim, M. M., Cha, J., Pan, Y., Park, J. H. (2020). Machine Learning-Based Network Sub-Slicing Framework in a Sustainable 5G Environment, Sustainability, 12(1), 6250-6251.

[27] Siddiqui, M. H. F. and Kumar, R. (2020). Interpreting the Nature of Rainfall with AI and Big Data Models. International Conference on Intelligent Engineering and Management (ICIEM), London, United Kingdom, 2020, 306-310.

[28] Bhuvana, R., \& Aithal, P. S. (2020). RBI Distributed Ledger Technology and Blockchain-A Future of Decentralized India. International Journal of Management, Technology, and Social Sciences (IJMTS), 5(1), 227-237.

[29] Rangi, P. K., \& Aithal, P. S. (2020). A Study on Blockchain Technology as a Dominant Feature to Mitigate Reputational Risk for Indian Academic Institutions and Universities. International Journal of Applied Engineering and Management Letters (IJAEML), 4(2), 275-284.

[30] Bhuvana, R., Madhushree, L. M., \& Aithal, P. S. (2020). Blockchain as a Disruptive Technology in Healthcare and Financial Services-A Review based Analysis on Current Implementations. International Journal of Applied Engineering and Management Letters (IJAEML), 4(1), 142-155.

[31] Bhuvana, R., \& Aithal, P. S. (2020). Blockchain based Service: A Case Study on IBM Blockchain Services \& Hyperledger Fabric. International Journal of Case Studies in Business, IT, and Education (IJCSBE), 4(1), 94-102.

[32] Gade, Dipak S. and Aithal, P. S. (2020). Aithal, P. S. (2020). Blockchain Technology: A Driving Force in Smart Cities Development. International Journal of Applied Engineering and Management Letters (IJAEML), 4(2), 237-252. 